\title{
Effect of Endothelin-1 on the Excitability of Rat Cortical and Hippocampal Slices In Vitro
}

\author{
R. KONOPKOVÁ ${ }^{1}$, I. VILAGI ${ }^{2}$, S. BORBELY ${ }^{2}$, H. KUBOVÁ ${ }^{1}$, J. OTÁHAL ${ }^{1}$
}

${ }^{1}$ Department of Developmental Epileptology, Institute of Physiology of the Academy of Sciences of the Czech Republic, Prague, Czech Republic, ${ }^{2}$ Department of Physiology and Neurobiology, Eötvös Loránd University, Budapest, Hungary

Received April 8, 2011

Accepted December 2, 2011

On-line January 31, 2012

\section{Summary}

Endothelin-1 (ET-1) is a neuroactive protein produced in most brain cell types and participates in regulation of cerebral blood flow and blood pressure. In addition to its vascular effects, ET-1 affects synaptic and nonsynaptic neuronal and glial functions. Direct application of ET-1 to the hippocampus of immature rats results in cerebral ischemia, acute seizures, and epileptogenesis. Here, we investigated whether ET-1 itself modifies the excitability of hippocampal and cortical circuitry and whether acute seizures observed in vivo are due to nonvascular actions of ET-1. We used acute hippocampal and cortical slices that were preincubated with ET-1 $(20 \mu \mathrm{M})$ for electrophysiological recordings. None of the slices preincubated with ET-1 exhibited spontaneous epileptic activity. The slope of the stimulus intensity-evoked response (input-output) curve and shape of the evoked response did not differ between ET-1-pretreated and control groups, suggesting no changes in excitability after ET- 1 treatment. The threshold for eliciting an evoked response was not significantly increased in either hippocampal or cortical regions when pretreated with ET-1. Our data suggest that acute seizures after intrahippocampal application of ET-1 in rats are likely caused by ischemia rather than by a direct action of ET-1 on brain tissue.

\section{Key words}

Endothelin-1 • Excitability - Hippocampus - Somatosensory cortex $\bullet$ Rat $\bullet$ Epileptogenesis

\section{Corresponding author}

J. Otáhal, Institute of Physiology of the Academy of Sciences of the Czech Republic, v.v.i., Department of Developmental
Epileptology, Vídeňská 1083, 14220 Prague 4, Czech Republic. Fax: +420 24106 2488. E-mail: jotahal@epilepsy.biomed.cas.cz

In the mammalian $\mathrm{CNS}$, the potent vasoconstrictor endothelin-1 (ET-1) is produced in neurons, in the endothelium of the cerebral microvessels, and in glial cells. Endothelins act through the G-proteincoupled receptors $\mathrm{ET}_{\mathrm{A}}$ and $\mathrm{ET}_{\mathrm{B}}$, which are differentially distributed among brain cell types. $\mathrm{ET}_{\mathrm{A}}$ is expressed in brain vascular cells, whereas $\mathrm{ET}_{\mathrm{B}}$ receptors are predominantly expressed in glial cells (Baba 1998). $\mathrm{ET}_{\mathrm{A}}$ receptors have high specificity for $\mathrm{ET}-1$, whereas $\mathrm{ET}_{\mathrm{B}}$ receptors are non-selective and accept all subtypes of endothelin nearly equally (Sakurai et al. 1990). Under physiological conditions, ET-1 contributes significantly to the regulation of blood pressure and cerebral blood flow. Moreover, ET-1 is now considered an important agent in the pathogenesis of hypertension (Hynynen and Khalil 2006). In addition to its vascular effects, ET-1 induces a wide range of physiological actions in the CNS. ET-1 is considered a neuropeptide because it influences the activity of ion channels, glutamate efflux (Rozyczka et al. 2004), glucose utilization (Sanchez-Alvarez et al. 2004), permeability of gap junctions (Blomstrand et al. 2004), and calcium signaling (Venance et al. 1997). Furthermore, higher ET-1 levels are found in the brains of patients with neurological disorders such as Alzheimer's disease, subarachnoidal hemorrhage, traumatic brain injury, and ischemia (Petrov et el. 2002, Rogers et al. 2003). 
A

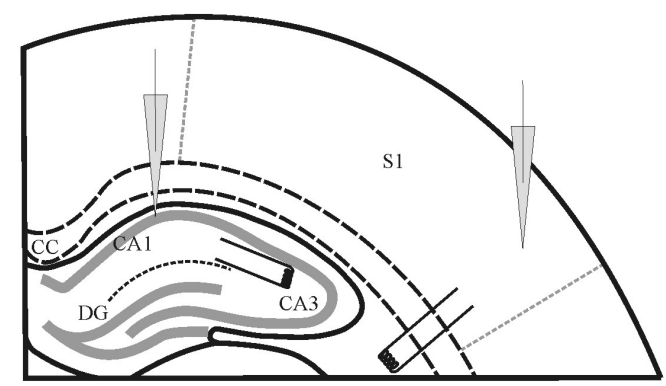

B
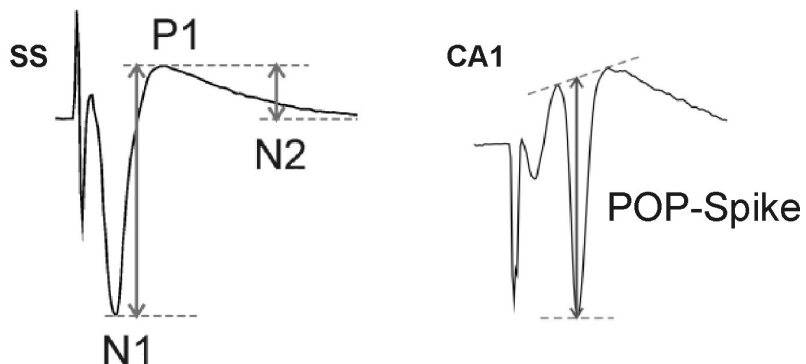

Fig. 1. A. To record evoked responses, the stimulation electrode was placed in Shaffer collaterals or at the border of the white and grey matter of the cortex. The recording electrode was positioned in the pyramidal layer of CA1 or layer III of the somatosensory cortex. B. Cortical (SS) and hippocampal (CA1) responses were evaluated by determining the peak-to-peak amplitude of the evoked response (POP spike or P1-N1).

Direct injection of ET-1 into the brain parenchyma leads to severe vasoconstriction and has been used as a model of focal cerebral ischemia with reperfusion in rats (Fuxe et al. 1997, Hughes et al. 2003). We have shown recently that intrahippocampal application of ET-1 in immature rats causes acute seizures (Tsenov 2007) with consequent epileptogenesis (Mateffyova 2006). Because ET-1 has significant effects on both neuronal and glial functions, our current study was designed to elucidate the direct effects of ET-1 on cortical and hippocampal excitability. We focused in particular on whether ET-1 itself alters hippocampal and cortical excitability. To abolish the dominant vascular effect of ET-1, we used hippocampal and cortical brain slices that were acutely preincubated with ET-1 for electrophysiological testing in vitro.

The experimental design was approved by the Eötvös University Animal Care Committee and by the Budapest Animal Health Care Authority. Animal care and experimental procedures were conducted in accordance with the guidelines of the European Community Council directive 86/609/EEC.

Experiments were performed on 25 slices (13 cortical and 12 hippocampal) prepared from 11 male Wistar rats (100-180 g, Toxicoop, Hungary). Rats were kept under a constant 12-h light/dark cycle and controlled temperature $\left(22 \pm 2{ }^{\circ} \mathrm{C}\right)$. Standard pellet food and tap water were available ad libitum. The preparation of tissue and the incubation procedure has been described in detail (Vilagi et al. 2008). Briefly, rats were deeply anaesthetized with chloral hydrate (Hungaropharma, Budapest) and decapitated. The brains were quickly removed, and coronal slices $(400 \mu \mathrm{m})$ were cut with a Vibratome (EMS-4000, Electron Microscopy Sciences, Fort Washington, PA, USA) in ice-cold artificial cerebrospinal fluid (aCSF). Slices contained both the somatosensory cortex and the hippocampus. After $30 \mathrm{~min}$ of regeneration in HEPES-buffered aCSF (pH 7.3-7.4, in $\mathrm{mM}: 120 \mathrm{NaCl} ; 2 \mathrm{KCl} ; 1.25 \quad \mathrm{KH}_{2} \mathrm{PO}_{4} ; 2 \quad \mathrm{MgSO}_{4}$; $20 \mathrm{NaHCO}_{3} ; 2 \mathrm{CaCl}_{2} ; 10$ glucose), slices were placed into a small $(2 \mathrm{ml})$ incubation chamber filled with buffered aCSF or ET-1 $(20 \mu \mathrm{M}$, Sigma Aldrich, Czech Republic) dissolved in aCSF for $30 \mathrm{~min}$. Slices were then transferred to an interface recording chamber and perfused with standard aCSF with a peristaltic pump $\left(2 \mathrm{ml} / \mathrm{min}\right.$; in $\mathrm{mM}$ : $126 \mathrm{NaCl} ; 26 \mathrm{NaHCO}_{3} ; 1.8 \mathrm{KCl} ; 1.25$ $\mathrm{KH}_{2} \mathrm{PO}_{4} ; 1.3 \quad \mathrm{MgSO}_{4} ; 2.4 \quad \mathrm{CaCl}_{2} ; 10$ glucose). All solutions were saturated with carbogene $\left(5 \% \mathrm{CO}_{2} /\right.$ $95 \% \mathrm{O}_{2}$ ) at $33 \pm 1{ }^{\circ} \mathrm{C}$.

For field potentials, recording extracellular glass microelectrodes (8-10 M $\Omega$ ) filled with $1 \mathrm{M} \mathrm{NaCl}$ were used. For cortical slices, a recording electrode was positioned into the lower part of Layer III of neocortex, and a bipolar tungsten stimulating electrode was positioned right below the recording electrodes at the border of the white and grey matter. For hippocampal slices, the Schaffer collaterals were stimulated, and evoked responses in the CA1 pyramidal layer were recorded (Fig. 1A). Signals were amplified with an Axoclamp 2A amplifier (Axon Instruments Inc., Union City, CA), filtered with a Supertech Signal Conditioner (Supertech Kft, Pécs, Hungary), digitized with a NI 6023E National Instruments A/D card, and recorded with the SPEL Advanced Intrasys computer program (Experimetria, Budapest, Hungary).

The viability of each slice was tested at the beginning of the procedure. When applying single pulse stimulation, characteristic field responses were recorded. Stimulus threshold (T) was determined $10 \mathrm{~min}$ after placing the slices into the recording chamber. For this we 
increased the stimulation intensity from 0 in small steps, and a stimulus strength just sufficient to produce a response was regarded as $1 \mathrm{~T}$. If the peak-to-peak amplitude of the maximal evoked response (P1-N1, Fig. 1B) was smaller than $1.0 \mathrm{mV}$, the slice was excluded from the experiments. The duration of the square voltage stimulation pulses was $100 \mu \mathrm{s}$, and the amplitude was gradually varied between threshold and supramaximal values. A short latency, early component of the evoked response was determined, which was characterized by the peak-to-peak amplitude of the first negative (N1) and positive (P1) peaks. For hippocampal recordings, the amplitude of the population spikes (POP spikes, Fig. 1B) and the slope of the EPSPs were determined. To obtain stimulus intensity-evoked responses (input-output, curve, I-O), the stimulation intensity was gradually increased from $1 \mathrm{~T}$ up to $4 \mathrm{~T}$ in six steps with interstimulus interval $10 \mathrm{~s}$ and response amplitudes were plotted against stimulation intensities. $10 \mathrm{~min}$ after transferring slices into the recording chamber medium, $2 \mathrm{~T}$ stimuli were delivered every $60 \mathrm{~s}$ for the following $60 \mathrm{~min}$ to detect possible long-lasting or washout effects.

The data reflect the mean \pm standard error of the mean (S.E.M.). For statistical comparisons between the control and experimental groups, an unpaired Student's $t$-test was used.

We did not observe any nonphysiological spontaneous electrical activity or seizures in both control and ET-1 pretreated slices. A typical evoked response was recorded in the cortical and hippocampal slices used in the experiment. Preincubation with ET-1 did not influence the shape and/or latency of the response (Fig. 2A, C). The slope of the I-O curve remained unchanged in both cortical (control 0.46 \pm 0.09 ; ET-1 preincubation $0.48 \pm 0.1$ ) and hippocampal slices (control $0.73 \pm 0.19 ; \quad$ ET-1 $0.72 \pm 0.17 ; \quad \mathrm{P}=0.97$ ) (Fig. 2A, C). Furthermore, pretreatment with ET-1 did not influence the amplitude of the evoked responses. The response to $2 \mathrm{~T}$ stimuli and the maximal response were unchanged in cortical (2T control $1.3 \pm 0.2 \mathrm{mV}$; ET-1 $1.3 \pm 0.3 \mathrm{mV}$, $\mathrm{P}=0.99$; maximal control $1.9 \pm 0.3 \mathrm{mV}$; ET-1 $1.9 \pm 0.4 \mathrm{mV}$, $\mathrm{P}=0.99)$ and hippocampal preparations (2T $1.8 \pm 0.4 \mathrm{mV}$; ET-1 1.8 $\pm 0.4 \mathrm{mV}, \mathrm{P}=0.95$; maximal $2.7 \pm 0.5 \mathrm{mV}$; ET-1 $2.8 \pm 0.5 \mathrm{mV}, \mathrm{P}=0.93)$. ET-1 preincubation tended to increase the threshold of evoked responses in both the hippocampus (control 2.3 $\pm 0.2 \mathrm{~V}$; ET-1 2.7 $\pm 0.3 \mathrm{~V}, \mathrm{P}=0.4$ ) and cortex (control 1.7 $\pm 0.2 \mathrm{~V}$; ET-1 2.3 $\pm 0.5 \mathrm{~V}, \mathrm{P}=0.3$ ). None of the analyzed parameters changed during this period in either region after ET-1 preincubation.
A

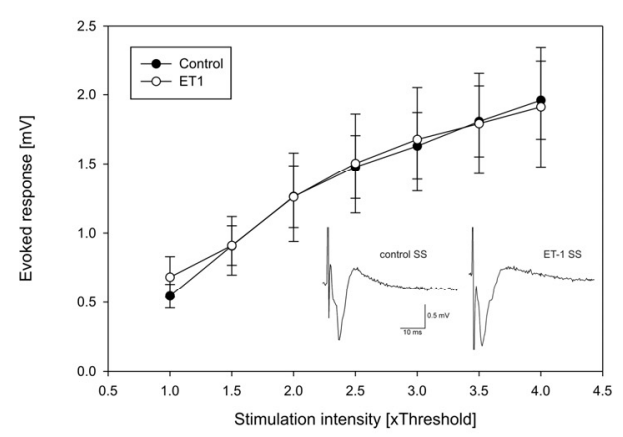

C

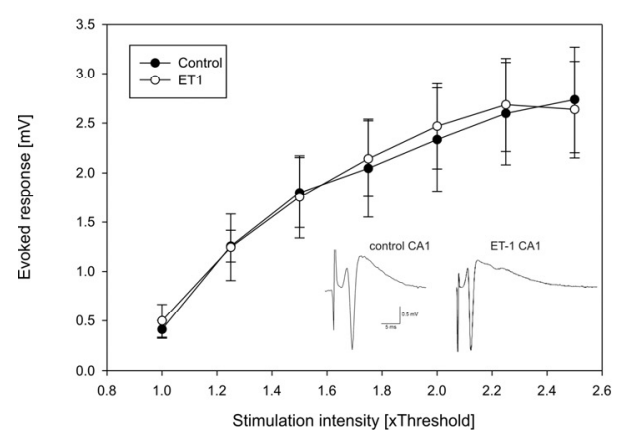

B

Threshold of cortical evoked response

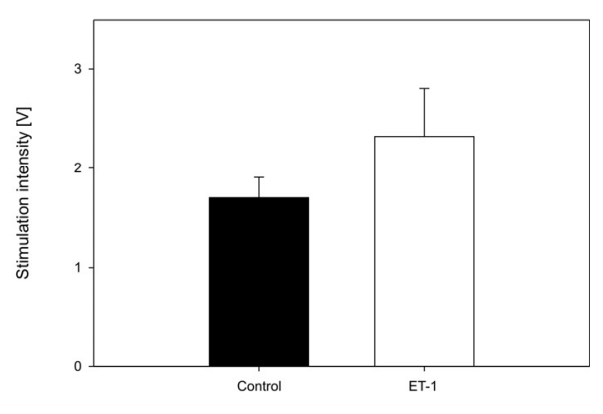

D

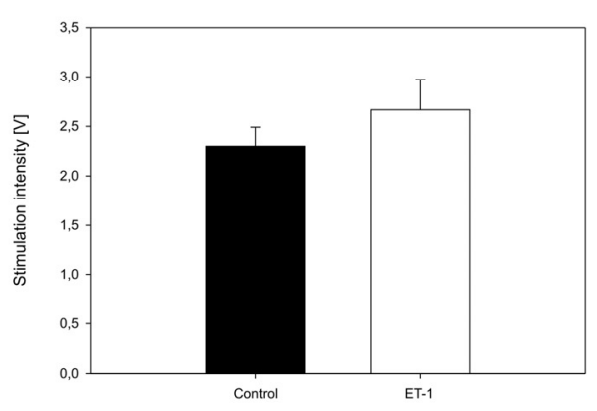

Fig. 2. ET-1 does not change the shape and latency of the evoked responses nor the slope of the I-O curve in either hippocampal or cortical preparations $(\mathbf{A}, \mathbf{C})$. The threshold of evoked responses was not significantly increased in either region (B, D). These results indicate no significant effect of ET-1 on the excitability of the nervous tissue. 
Although data about the direct effects of ET-1 on neuronal excitability are sparse, increased neuronal excitability after a brief ET-1 exposure was demonstrated by Feng and Strichartz (Feng and Strichartz 2009). They found increased firing and decreased rectifying potassium current in dissociated neurons from the dorsal root ganglia. Moreover, neurons from the nucleus of the solitary tract increase their neuronal activity upon iontophoretic ET-1 application and augment the responses to glutamate in acute brain slices (Shihara et al. 1998). Increased glutamate reactivity and neuronal firing can be caused by inhibition of astrocytic glutamate transport by ET-1 (Leonova et al. 2001). However, this group found this effect only in selected neuronal populations, suggesting that the ET-1-induced increase in neuronal excitability is highly specific and not universally seen in neuronal tissue. ET-1 has a direct inhibitory effect on gap junctions between astrocytes, affecting their electrical coupling, intercellular communication, and spatial potassium buffering (Blomstrand et al. 2004). It has been shown that affected astrocytic gap junction coupling in connexin43-deficient mice is responsible for the reduced threshold for the generation of epileptiform events (Wallraff et al. 2006) and that a connexin-43 mimetic peptide has pronounced anticonvulsive actions in vitro (Samoilova et al. 2008). However, in our current set of experiments, we did not detect changes in spontaneous activity or changes in basal excitability in either hippocampal or cortical preparations.

The absence of direct effects of ET-1 on network excitability supports our hypothesis that acute seizures induced by parenchymal injection of ET-1 are likely caused by an indirect effect of ET-1 on brain tissue. Using continual video/EEG monitoring, we previously demonstrated development of epileptic seizures coupled with tissue destruction after intrahippocampal injection of ET-1 in freely moving rats. On an EEG, seizures persisted for at least $24 \mathrm{~h}$ after ET-1 administration, and their severity was dose dependent (Tsenov et al. 2007). Development of seizures immediately after ischemic insult was described in a model of middle cerebral artery occlusion in adult rats. Hartings and collaborators (Hartings et al. 2003) demonstrated spontaneous seizures in animals with permanent occlusion and animals subjected to transient ischemia with reperfusion. Furthermore, in immature CD1 mice, ligation of the unilateral carotid artery without general hypoxia induced behavioral seizures in $75 \%$ of animals (Comi et al. 2004). Thus focal ischemia can trigger seizures regardless of the mechanisms of its induction. The depolarization of cell membranes during cerebral ischemia and/or hypoxia results in glutamate release (Perlman 2006). Systemic or focal administration of excitatory amino acids or agonists of their respective receptors induces seizures (reviewed in Mares et al. 2004). Therefore, an ischemia-induced increase in glutamate levels is likely responsible for seizure development in a model of focal ischemia provoked by parenchymal injection of ET-1. Also, results of other studies support this mechanism. Due to the already mentioned direct interactions of ET-1 with both glial and neuronal cells, ET-1 can consequently aggravate both ictogenic and neurodestructive effects of ET-1-induced focal ischemia. Our study was not focused on this interaction, but its role should be analyzed further.

Our data suggest that acute seizures after intraparenchymal injection of ET-1 are caused by its ability to reduce focal blood flow rather than by direct action of ET-1 on brain tissue.

\section{Conflict of Interest}

There is no conflict of interest.

\section{Acknowledgements}

This project was supported by grant nos. 305/08/H037 from the Czech Science Foundation, LC554 from the Ministry of Education of the Czech Republic, Research Projects AV0Z50110509 and 1QS501210509 from the Academy of Sciences of the Czech Republic, and CZ-7/04 from the Ministry of Education of Hungary.

\section{References}

BABA A: Role of endothelin B receptor signals in reactive astrocytes. Life Sci 62: 1711-1715, 1998.

BLOMSTRAND F, VENANCE L, SIREN A L, EZAN P, HANSE E, GLOWINSKI J, EHRENREICH H, GIAUME C: Endothelins regulate astrocyte gap junctions in rat hippocampal slices. Eur J Neurosci 19: 1005-1015, 2004.

COMI AM, WEISZ CJ, HIGHET BH, JOHNSTON MV, WILSON MA: A new model of stroke and ischemic seizures in the immature mouse. Pediatr Neurol 31: 254-257, 2004. 
FENG B, STRICHARTZ G: Endothelin-1 raises excitability and reduces potassium currents in sensory neurons. Brain Res Bull 79: 345-350, 2009.

FUXE K, BJELKE B, ANDBJER B, GRAHN H, RIMONDINI R, AGNATI LF: Endothelin-1 induced lesions of the frontoparietal cortex of the rat. A possible model of focal cortical ischemia. Neuroreport 8: 2623-2629, 1997.

HARTINGS JA, WILLIAMS AJ, TORTELLA FC: Occurrence of nonconvulsive seizures, periodic epileptiform discharges, and intermittent rhythmic delta activity in rat focal ischemia. Exp Neurol 179: 139-149, 2003.

HUGHES PM, ANTHONY DC, RUDDIN M, BOTHAM MS, RANKINE EL, SABLONE M, BAUMANN D, MIR AK, PERRY VH: Focal lesions in the rat central nervous system induced by endothelin-1. J Neuropathol Exp Neurol 62: 1276-1286, 2003.

HYNYNEN MM, KHALIL RA: The vascular endothelin system in hypertension - recent patents and discoveries. Recent Pat Cardiovasc Drug Discov 1: 95-108, 2006.

LEONOVA J, THORLIN T, ABERG ND, ERIKSSON PS, RONNBACK L, HANSSON E: Endothelin-1 decreases glutamate uptake in primary cultured rat astrocytes. Am J Physiol Cell Physiol 281: C1495-C1503, 2001.

MARES P, FOLBERGROVA J, KUBOVA H: Excitatory aminoacids and epileptic seizures in immature brain. Physiol Res 53 (Suppl 1): S115-S124, 2004.

MATEFFYOVA A, OTAHAL J, TSENOV G, MARES P, KUBOVA H: Intrahippocampal injection of endothelin-1 in immature rats results in neuronal death, development of epilepsy and behavioral abnormalities later in life. Eur $J$ Neurosci 24: 351-360, 2006.

PERLMAN JM: Intervention strategies for neonatal hypoxic-ischemic cerebral injury. Clin Ther 28: 1353-1365, 2006.

PETROV T, STEINER J, BRAUN B, RAFOLS JA: Sources of endothelin-1 in hippocampus and cortex following traumatic brain injury. Neuroscience 115: 275-283, 2002.

ROGERS SD, PETERS CM, POMONIS JD, HAGIWARA H, GHILARDI JR, MANTYH PW: Endothelin B receptors are expressed by astrocytes and regulate astrocyte hypertrophy in the normal and injured CNS. Glia 41: 180-190, 2003.

ROZYCZKA J, FIGIEL M, ENGELE J: Endothelins negatively regulate glial glutamate transporter expression. Brain Pathol 14: 406-414, 2004.

SAKURAI T, YANAGISAWA M, TAKUWA Y, MIYAZAKI H, KIMURA S, GOTO K, MASAKI T: Cloning of a cDNA encoding a non-isopeptide-selective subtype of the endothelin receptor. Nature 348: 732-735, 1990.

SAMOILOVA M, WENTLANDT K, ADAMCHIK Y, VELUMIAN AA, CARLEN PL: Connexin 43 mimetic peptides inhibit spontaneous epileptiform activity in organotypic hippocampal slice cultures. Exp Neurol 210: 762-775, 2008.

SANCHEZ-ALVAREZ R, TABERNERO A, MEDINA JM: Endothelin-1 stimulates the translocation and upregulation of both glucose transporter and hexokinase in astrocytes: relationship with gap junctional communication. J Neurochem 89: 703-714, 2004.

SHIHARA M, HIROOKA Y, HORI N, MATSUO I, TAGAWA T, SUZUKI S, AKAIKE N, TAKESHITA A: Endothelin-1 increases the neuronal activity and augments the responses to glutamate in the NTS. Am J Physiol 275: R658-R665, 1998.

TSENOV G, MATEFFYOVA A, MARES P, OTAHAL J, KUBOVA H: Intrahippocampal injection of endothelin-1: a new model of ischemia-induced seizures in immature rats. Epilepsia 48 (Suppl 5): 7-13, 2007.

VENANCE L, STELLA N, GLOWINSKI J, GIAUME C: Mechanism involved in initiation and propagation of receptor-induced intercellular calcium signaling in cultured rat astrocytes. J Neurosci 17: 1981-1992, 1997.

VILAGI I, KISS DS, FARKAS A, BORBELY S, TARNOK K, HALASY K, BANOCZI Z, HUDECZ F, FRIEDRICH P: Synthetic calpain activator boosts neuronal excitability without extra $\mathrm{Ca}^{2+}$. Mol Cell Neurosci 38: 629-636, 2008.

WALLRAFF A, KOHLING R, HEINEMANN U, THEIS M, WILLECKE K, STEINHAUSER C: The impact of astrocytic gap junctional coupling on potassium buffering in the hippocampus. $J$ Neurosci 26: 5438-5447, 2006. 